\title{
25 Research Square \\ Rapid Detection of Avian Leukosis Virus Subgroup J by Cross-priming Amplification
}

\section{Yong Xiang}

South China Agricultural University https://orcid.org/0000-0001-6164-094X

\section{Lizhen Li}

South China Agricultural University

\section{Peng Liu}

South China Agricultural University

Ling Yan

South China Agricultural University

\section{Zeng Jiang}

South China Agricultural University

\section{Yun Yu}

South China Agricultural University

Yu Li

South China Agricultural University

\section{Xiaoyan Chen}

South China Agricultural University

Weisheng Cao ( $\nabla$ caoweish@scau.edu.cn )

\section{Research}

Keywords: Avian leukosis virus subgroup J, Cross-priming amplification, Rapid detection, Nucleic acid detection

Posted Date: January 23rd, 2020

DOI: https://doi.org/10.21203/rs.2.21696/v1

License: (c) (i) This work is licensed under a Creative Commons Attribution 4.0 International License. Read Full License

Version of Record: A version of this preprint was published at Scientific Reports on May 26th, 2021. See the published version at https://doi.org/10.1038/s41598-021-90479-x. 


\section{Abstract}

Avian leukosis virus subgroup $\mathrm{J}(\mathrm{ALV}-\mathrm{J})$ causes oncogenic disease in chickens in China, resulting in great harm to poultry production. Herein, we employed a cross-priming amplification (CPA) approach and a nucleic acid detection device to establish a visual rapid detection method for ALV-J. When the amplification reaction was carried out at $60^{\circ} \mathrm{C}$ for just $60 \mathrm{~min}$, the sensitivity of CPA was 10 times higher than conventional PCR, with high specificity, based on detection of 123 clinical plasma samples. The coincidence rate with real-time PCR was 97.3\% (71/73). CPA detection of ALV-J does not require an expensive PCR instrument; a simple water bath or incubator is sufficient for complete DNA amplification, and the closed nucleic acid detection device avoids aerosol pollution, making judgment of results more intuitive and objective. The CPA assay would be a promising simple, rapid and sensitive method for identification of ALV-J.

\section{Background}

Avian Leukosis ( $A L$ ) is an infectious tumour disease affecting poultry caused by avian leukosis viruses (ALVs) belonging to the Alpharetrovirus genus of the family Retroviridae [1]. Chickens infected with ALVs suffer from decreased performance and immunosuppression, leading to tumours and even death [2], and it is one of the most important diseases endangering the healthy development of the poultry industry in China [3]. Based on the envelope glycoprotein (gp85) associated with subgroup specificity, ALVs from naturally infected chicken flocks can be divided into seven subgroups (A, B, C, D, E, J and K) [4], among which endogenous subgroup $E$ viruses with little to no pathogenicity are present in nearly all chicken lines, while the others are exogenous and pathogenic $[5,6]$. Subgroup $A$ and $B$ viruses mainly cause lymphocytic leukemia and myeloid leukosis in field flocks [7, 8], while flocks naturally infected with subgroup $C$ and $D$ are rarely observed in the field $[9,10]$.

Avian leukosis virus subgroup J (ALV-J) was first isolated and identified in broiler chickens in 1988 [11]. Chickens infected with ALV-J can suffer from medulloblastoma and decreased production performance, causing huge economic losses to the poultry breeding industry across the world [12]. ALV-J was originally thought only to infect meat-type chickens [13], but its host range is now known to include layer chickens and local broiler breeders in most parts of China $[14,15]$, and the disease has even spread to waterfowl and wild birds [16]. Most large foreign breeder companies had eradicated classic exogenous ALVs by the end of the 1980s, but ALV-J remains widespread in China [17].

Effective vaccines and drugs have not yet been reported for AL. Obtaining a population of breeding poultry without exogenous ALV through continuous purification is therefore the main method for disease prevention and control, for which virus detection is crucial. A variety of methods for detecting and differentially diagnosing ALV have been established in various regions of the world, mainly involving virus isolation and identification [18], pathological diagnosis [19], serological detection methods such as enzyme-linked immunosorbent assay (ELISA) [20], and PCR-based molecular biological detection [21]. However, existing detection methods have some limitations and shortcomings. For example, traditional 
virus isolation and identification is too time-consuming to meet the requirements of rapid diagnosis, and PCR and real-time PCR (RT-PCR) require expensive instruments and equipment which are not conducive to fieldwork. Additionally, while the loop-mediated isothermal amplification (LAMP) detection method does not require specific instruments or equipment [22], it is highly prone to false positives, weak positive results tend to be inaccurate, and contamination by aerosols can occur easily.

Cross-priming amplification (CPA) is a rapid detection method developed in recent years [23-25]. The CPA utilizes multiple primers and probes ( $4 \mathrm{~s}, 5 \mathrm{a}, 2 \mathrm{a} 1 \mathrm{~s}, 3 \mathrm{a}$, and $2 \mathrm{a}$ ) to amply nucleotide sequence isothermally. By labelling primer 2a with biotin, primer 3a with FITC, then the amplified products were recognized by anti-biotin and anti-FITC monoclonal antibodies on the test line, where gold nanoparticles (AuNPs) were fixed, CPA amplified products could be visualized in nucleic acid test strip [26]. It benefits from high specificity and sensitivity, does not require expensive instruments, the operation process is relatively simple, amplification is rapid, and it can be used with disposable nucleic acid detection strip in closed tubes, thereby avoiding aerosol pollution, making results more intuitive and objective [27]. This method has been applied to the diagnosis of infectious diseases and the detection of multiple pathogens $[24,28]$. In the present study, we developed a CPA assay for ALV-J, which would be a promising and userfriendly rapid detection method.

\section{Methods}

\section{Main experimental materials and reagents}

ALV-J (HN06), ALV-A (GD-13), ALV-B (CD08), ALV-K (GDFX0601), ALV-E (HN1301) and Salmonella enteritis (SE) were maintained in our laboratory. Escherichia coli ATCC15922 and Pseudomonas aeruginosa (PA)ATCC27853 were obtained from HuanKai Microbial (Guangzhou, China). Mycoplasma gallisepticum (MG) S6 was donated by Professor Ding (College of Veterinary Medicine, South China Agricultural University). Bst DNA polymerase, $10 \times$ ThermoPol Reaction Buffer, dNTPs and $\mathrm{MgSO}_{4}$ were products of New England Biolabs (Beverley, MA, USA). Betaine was acquired from Sigma (St. Louis, MO, USA). Disposable Nucleic Acid Detection Strips were purchased from Ustar (Hangzhou, China). The DNA Extraction Kit, Gel Extraction Kit, and Plasmid Mini Kit were produced from OMEGA (Norcross, GA, USA).

\section{Primer design}

Using ALV-J sequences published in the NCBI database (GeneBank ID: HQ900844.1, HM776937.1, JQ935966.1 and Z46390.1), online software PrimerExpoler (http://primerexplorer.jp/e/), Primer Premier 5.0 and Oligo 7 were used to design CPA primers and probes for the envelope glycoprotein gene of ALV-J. The primers set include two external primers (F3 and B3), one cross-amplification primer CPR consisting of two short primers (F2 and B2), two detection probes F1 (labelled at the 5 ' end with FAM) and F2 (labelled at the $5^{\prime}$ end with biotin) (Table 1). The single primer B2 does not participate in the reaction system, it's only a part of the sequence of primer CPR. The amplified envelope glycoprotein gene fragment was $548 \mathrm{bp}$. The specific positions and sequence of primers and probes in the genome are 
shown in Fig. 1 and Table 1. These primers and probes were synthesised by Sangon Biotech (Shanghai, China) and diluted to $10 \mu \mathrm{mol} \mathrm{L}{ }^{-1}$ before use.

\section{DNA extraction and quantification of recombinant plasmid standards}

Total DNA was extracted from DF- 1 cells $\left(2.5 \times 10^{6}\right.$ cells $)$ infected with ALV-J $\left(2 \times 10^{3}\right.$ TCID $\left._{50}\right)$ using an DNA Extraction kit (OMEGA, Norcross, GA) according to the manufacturer's instructions and stored at $-20^{\circ} \mathrm{C}$ until use. The PCR amplification system and reaction conditions for the 548 bp target fragment amplified using primer F3 and B3 comprised $10 \mu \mathrm{L}$ of $2 \times$ Premix r Taq (YEASE, Shanghai, China), $1 \mu \mathrm{L}$ of primer F3 $\left(10 \mu \mathrm{mol} \mathrm{L}^{-1}\right)$ and B3 $\left(10 \mu \mathrm{mol} \mathrm{L}^{-1}\right), 1 \mu \mathrm{L}$ of total DNA template $(100 \mathrm{ng} / \mu \mathrm{L}$,$) , and deionised$ water up to $20 \mu \mathrm{L}$. An PCR System (Applied Biosystems, FosterCity, CA) was used for amplification with 1 cycle of $95^{\circ} \mathrm{C}$ for $5 \mathrm{~min}, 40$ cycles of $95^{\circ} \mathrm{C}$ for $1 \mathrm{~min}, 55^{\circ} \mathrm{C}$ for $1 \mathrm{~min}$ and $72{ }^{\circ} \mathrm{C}$ for $1 \mathrm{~min}, 1 \mathrm{cycle}$ of $72^{\circ} \mathrm{C}$ $5 \mathrm{~min}$. The PCR product was recovered and cloned into the PMD-18T vector according to the manufacturer's instructions (Takara, Japan), recombinants were transformed into E. coli DH5a competent cells (Takara, Japan), monoclonal clones were selected on LB plates containing ampicillin, DNA was extracted from positive clones using a Plasmid Mini Kit (OMEGA, Norcross, GA), and sent to Sangon Biotech (Shanghai, China) for DNA sequencing. Plasmid concentration were measured by UV spectroscopy (Thermo, USA ) and the recombinant plasmid copy number was calculated according to the formula: number of copies $=\left(\right.$ concentration in $\left.\mathrm{ng} \times 6.02 \times 10^{23}\right) /\left(\right.$ genome length $\left.\times 10^{9} \times 660\right)[29]$, and the samples were stored at $-20^{\circ} \mathrm{C}$ until use.

\section{Establishment of the basic amplification system and optimisation of reaction conditions}

The basic CPA reaction system was established as described previously [30]. Reactions were performed a $25 \mu \mathrm{L}$ total volume in $0.2 \mathrm{~mL}$ centrifuge tube, which containing $1 \times$ Thermo Pol Buffer, $0.4 \mathrm{~mol} \mathrm{~L}^{-1}$ of Betaine, $0.8 \mathrm{mmol} \mathrm{L}{ }^{-1}$ of dNTPs, $4 \mathrm{mmol} \mathrm{L}^{-1}$ of $\mathrm{Mg}^{2+}, 8$ units of Bst DNA polymerase, $0.8 \mu \mathrm{mol} \mathrm{L}^{-1}$ of CPR primer, $0.6 \mu \mathrm{mol} \mathrm{L} \mathrm{L}^{-1}$ of F1 primer, $0.6 \mu \mathrm{mol} \mathrm{L}{ }^{-1}$ of F2 primer, $0.4 \mu \mathrm{mol} \mathrm{L}^{-1}$ of F3 primer, $0.4 \mu \mathrm{mol} \mathrm{L}^{-1}$ of B3 primer and $2.0 \mu \mathrm{L}$ of template DNA. The reaction was carried out at $60^{\circ} \mathrm{C}$ for 60 min. The products were detected by $2 \%$ agarose gel electrophoresis in $1 \times$ TAE with EB staining and the Disposable Nucleic Acid Detection Strip (Ustar, Hangzhou, China) according to the manufacturer's instructions, when CPA amplification was completed. In brief, the $0.2 \mathrm{~mL}$ centrifuge tube after the reaction is embedded in the Disposable Nucleic Acid Detection Strip, then press the handle forcefully, and observe the results after 510 minutes. Recombinant plasmid standards and $\mathrm{ddH}_{2} \mathrm{O}$ were used as positive template and negative controls, respectively. The basic reaction system could then be optimised if applicable. As shown in Table 2, different concentrations of primers were optimised, and each combination included a negative control. The reaction system was used to optimise the concentration of betaine, $\mathrm{Mg}^{2+}$, dNTPs and Bst DNA polymerase by varying each one in turn. Finally, the reaction temperature and time were optimised. All these analyses were repeated three times. 


\section{Specificity and Sensitivity of the CPA assay}

DNA was extracted from PA, SE, E. coli, MG and DF-1 cells infected with ALV-J, ALV-A, ALV-B, ALV-K and ALV-E using an SQ tissue DNA kit (OMEGA) according to the manufacturer's instructions. The specificity of the CPA method was determined using the above nucleic acids as templates. A 10-fold dilution series of ALV-J recombinant plasmid DNA was prepared using sterile $\mathrm{ddH}_{2} \mathrm{O}$, and different concentrations of plasmid DNA were amplified by the CPA assay, conventional PCR (F3 and B3 as primes, described above), and RT-PCR [31]. RT-PCR was carried out in a $20 \mu \mathrm{L}$ reaction volume containing $10 \mu \mathrm{L} 2 \times$ iTaq Universal SYBR Green Supermix (BioRad, Hercules, CA), $1.0 \mu \mathrm{L}$ each primer (Forward: 5'-

TGTGTGCGTGGTTATTATTTC-3', Reverse: 5'-AATGGCGAGGTCGCTGA CTGC-3') (10 pmol $\left.\mu \mathrm{L}^{-1}\right), 1 \mu \mathrm{L}$

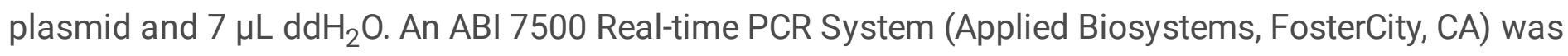
used for amplification with 1 cycle of $95^{\circ} \mathrm{C} 3 \mathrm{~min} ; 40$ cycles of $95^{\circ} \mathrm{C}$ for $15 \mathrm{~s}$ and $60^{\circ} \mathrm{C}$ for $34 \mathrm{~s}$. Fluorescence signals were collected after each amplification step. All these analyses were repeated three times.

\section{Detection of ALV-J in clinical plasma samples}

During the purification of exogenous avian leukosis, according to ELISA, positive ALV p27-positive plasma samples ( $/ \mathrm{P}>0.2)$ were collected to be screened using the ALV-J CPA method, routine PCR (F3 and B3 as primers), and RT-PCR [31] to measure coincidence rates for the three methods. Additionally, plasma samples with $0.1 \leq \mathrm{S} / \mathrm{P} \leq 0.2$ according to ELISA analysis of p27 were also tested using the above three methods, and the sensitivity of the three methods was compared. All these analyses were repeated three times.

\section{Results}

\section{Calculation of plasmid DNA copy number}

The extracted plasmid DNA was assessed by spectrophotometer at a concentration of $66 \mathrm{ng} \mathrm{\mu L}^{-1}$. The purity was 1.94, the length of the pMD-18T vector was $2692 \mathrm{bp}$, the length of the insert was $548 \mathrm{bp}$, hence the total number of bases was $3240 \mathrm{bp}$, and the concentration was calculated to be $1.86 \times 10^{10}$ copies $\mu \mathrm{L}^{-1}$.

\section{Establishment of the basic amplification system}

The CPA product was observed under ultraviolet light following electrophoresis. The CPA products gave a ladder-like pattern on the agarose gel, result of their characteristic structure, but the control was negative (Fig. 2a). The results of Disposable Nucleic Acid Detection Strip showed that the positive control containing the recombinant plasmid as template yield red bands on both the control line (C) and the test line $(T)$, while the negative control group only yielded a positive result for the $C$ line (Fig. 2b), which suggests that the basic CPA reaction system could amplify ALV-J effectively.

\section{Optimization of the reaction system and conditions}


The optimal primers concentration was primer group 7 (Fig. 3), based on their clearest and brightest strips. Optimal concentrations for $\mathrm{Mg}^{2+}$, betaine, dNTPs and Bst DNA polymerase in the amplification system were $4 \mathrm{mmol} \mathrm{L}^{-1}$ for $\mathrm{Mg}^{2+}$ (Fig. 4), $0.2 \mathrm{~mol} \mathrm{~L}^{-1}$ for Betaine (Fig. 5), $0.8 \mathrm{mmol} \mathrm{L}^{-1}$ for dNTPs (Fig. 6), and $8 \mathrm{U}$ for Bst DNA polymerase (Fig. 7). The reaction system was tested at 54, 55, 56, 57, 58, 59, $60,61,62,63,64$ and $65^{\circ} \mathrm{C}$ for 60 min respectively, and the optimal temperature was $60{ }^{\circ} \mathrm{C}$ (Fig. 8).

\section{Optimization of the ALV-J CPA assay reaction time}

The ALV-J CPA reaction system was tested at $60^{\circ} \mathrm{C}$ for $15,30,45,60,75,90,105$ and 120 min, and production amplification was most effective at $60 \mathrm{~min}$; when the amplification time was increased beyond this, the efficiency diminished. Therefore, 60 min was optimal reaction time (Fig. 9). The optimal reaction system and conditions for ALV-J CPA amplification are shown in Table 3.

\section{Specificity of the ALV-J CPA assay}

Specific experiments were carried out using the optimal reaction system and conditions for ALV-J CPA. The results showed that only recombinant plasmid standards and ALV-J CDNA yielded positive results in both test line and control line, while ALV-A, ALV-B, ALV-K, ALV-E, PA, E.coli, SE and MG yielded only positive results in control line (Fig. 10), indicating that the ALV-J CPA detection method is highly specific.

\section{Evaluation of the Sensitivity of the CPA assay}

Sensitivity tests were carried out using the optimal reaction system for CPA. The results showed that when the plasmid DNA concentration was between $1.86 \times 10^{1}$ and $1.86 \times 10^{10}$ copies $\mu \mathrm{L}^{-1}$, identification was feasible with nucleic acid test strips. By contrast, only the control line was positive at $1.86 \times 10^{-}$ ${ }^{1}-1.86$ copies $\mu \mathrm{L}^{-1}$, hence the detection limit of the ALV-J CPA method was $1.86 \times 10^{1}$ copies. The results of conventional PCR amplification showed that the target band was amplified at $1.86 \times 10^{2}-1.18 \times 10^{10}$ copies $\mu \mathrm{L}^{-1}$, equating to a detection limit of $1.86 \times 10^{2}$ copies (Fig. 11). Thus, the sensitivity of ALV-J CPA was up to 10 times higher than that of conventional PCR.

\section{Detection of ALV-J in clinical plasma samples}

A total of 48 ALV p27-positive plasma samples (S/P >0.2) and 75 plasma samples with $0.1 \leq S / P \leq 0.2$ based on ELISA were tested for ALV-J using the CPA method, conventional PCR, and RT-PCR. The results showed that, among the 48 samples with $S / P>0.2$, the positive rates for CPA, real-time PCR and PCR were $54.2 \%(26 / 48), 54.2 \%(26 / 48)$ and $52.1 \%(25 / 48)$, respectively. The results for CPA and RT-PCR were consistent, and the coincidence rate with the PCR method was $96.2 \%(25 / 26)$. Detailed results are shown in Table 4. Among the 75 plasma samples with $0.1 \leq \mathrm{S} / \mathrm{P} \leq 0.2$, the positive rates for CPA, RT-PCR and PCR were 60.0\% (45/75), 62.6\% (47/75) and 38.7\% (29/75), respectively. Detailed results are shown in Table 5. The sensitivity of the ALV-J CPA assay was higher than that of conventional PCR, which was comparable with RT-PCR. The coincidence rate between CPA and RT-PCR was $97.3 \%$ (71/73) across all 123 plasma samples. 


\section{Discussion}

ALV-J infection currently causes great economic losses in China [17], and it presence is associated with a variety of tumour types including myeloma, renal tumours and hemangioma [19, 32]. The high incidence of tumours reduces production, and virus elimination increases production costs. In order to meet the need for rapid diagnosis, it is necessary to develop a simple, rapid and sensitive diagnostic method for detecting ALV-J. The isolation and identification of viruses by cell culture is expensive and timeconsuming. Conventional PCR and real-time PCR is an established method for detecting ALV-J [31], but it requires high-precision instruments, skilled operators, and the amplification time is 3 to $4 \mathrm{~h}$. Additionally, it is difficult to adapt this method for rapid detection of ALV-J in the field. ELISA is a method that can potentially solve this problem since it can determine whether a sample contains ALV p27 antigen, but it cannot be used for the identification of ALV subgroups, nor can it distinguish exogenous from endogenous ALV.

In recent years, researchers have paid increasing attention to new detection methods based on molecular biology. Compared with traditional PCR, pathogen separation and similar methods, CPA is a new gene amplification approach with many advantages. One of the most important features of CPA is its high amplification efficiency and sensitivity. Even a small number of templates can produce a large number of amplification products [30]. The application of CPA technology not only overcomes the dependence on PCR and RT-PCR instruments, but also affords an operational procedure that is simple and accurate, and interpretation of results is more objective, convenient and intuitive than the case for loop-mediated isothermal amplification (LAMP), since it avoids subjectivity [22]. CPA technology facilitates molecular biology-based detection by non-specialist laboratories and economically underdeveloped areas, which is of great significance for the scientific research of nucleic acids and viral diseases [33].

In the process of developing a successful CPA assay, we found that primer design was crucial [25]. For accurate detection, the primers play a vital role in ensuring specificity and sensitivity in this assay and their design is one of the difficulties of CPA. Because the CPA assay makes use of five primers to recognize five distinct regions on the target DNA sequence, which makes the CPA assay more specific than conventional PCR using two primers [26]. The presence of multiple primers in the same tube can result in non-specific amplification leading to false positives and misleading detection results [34]. Before determining the final ALV-J CPA primers, we had made a lot of preliminary experiments to screen multiple primer sets and eliminated those giving non-specific amplification products.

In the present study, a rapid CPA detection method for ALV-J was established. Optimal reaction conditions were $60^{\circ} \mathrm{C}$ for $60 \mathrm{~min}$, and the sensitivity was 10 times that of conventional PCR. The assay proved negative for other ALV subgroups, and other virus, and bacteria. ALV p27-positive plasma samples $(S / P>0.2)$ were tested using the CPA method, and the results were consistent with those of RT-PCR; the coincidence rate with PCR was $96.2 \%$. When ALV-J CPA was used to detect a non-positive plasma sample with $0.1 \leq \mathrm{S} / \mathrm{P} \leq 0.2$, the method exhibited the same excellent sensitivity as RT-PCR, and the detection rate was higher than that of conventional PCR. Statistical analysis of CPA and RT-PCR detection rates for 
all 123 clinical plasma samples showed that the coincidence rate of the two methods was $97.3 \%(71 / 73)$, indicating that the CPA detection method for ALV-J established in this study can be applied for rapid onsite diagnosis of ALV-J and screening of samples.

\section{Conclusions}

In summary, the established ALV-J CPA method has significant advantages for the detection of ALV-J. It is convenient to execute, exhibits strong specificity, high sensitivity, and does not require complicated experimental equipment, making it suitable for analysis outdoors and in primary medical units. It is an ideal system for rapid detection of ALV-J with great potential for monitoring this viral disease.

\section{Abbreviations}

AL: Avian Leukosis; ALV: Avian leukosis virus; ALV-J: Avian leukosis virus subgroup J; CPA: Cross-priming amplification; ELISA: enzyme-linked immunosorbent assay; PCR: Polymerase Chain Reaction; RT-PCR: real-time PCR; LAMP: loop-mediated isothermal amplification.

\section{Declarations}

\section{Ethics approval and consent to participate}

The plasma samples were from yellow chickens of Guangdong province in China during an ALV epidemiological investigation conducted by our laboratory. And all the chicken plasma sampling procedures were approved by the Animal Care and Use Committee of Guangdong Province, China (2018B110). Our sampling processes were assisted by local authorities and veterinarians.

\section{Consent for publication}

Not applicable.

\section{Availability of data and materials}

Not applicable.

\section{Competing interests}

The authors declare that they have no competing interests.

\section{Funding}

This study is supported by Key-Area Research and Development Program of Guangdong Province (2019B020217002); the Guangdong Poultry Industry Technology System (2019KJ128); and the China Meat-Type Chicken Research System (CARS-41-G16). 


\section{Authors' contributions}

WC and $Y X$ conceived and designed the study. YX performed the experiments. YX, LL and PL analyzed the data. YX and WC wrote the paper. All authors read and approved the final manuscript.

\section{Acknowledgements}

Not applicable.

\section{Authors' information}

${ }^{1}$ College of Veterinary Medicine, South China Agricultural University, Guangzhou 510642, P.R.China.

${ }^{2}$ Key Laboratory of Zoonosis Prevention and Control of Guangdong Province, South China Agricultural University, Guangzhou 510642, P.R.China.

${ }^{3}$ Guangdong Laboratory for Lingnan Modern Agriculture, Guangzhou 510642, P.R.China. ${ }^{4}$ National and Regional Joint Engineering Laboratory for Medicament of Zoonosis Prevention and Control, South China Agricultural University, Guangzhou 510642, P.R.China.

${ }^{5}$ South China Collaborative Innovation Centre for Prevention and Control of Poultry Infectious Diseases and Safety of Poultry Products, South China Agricultural University, Guangzhou 510642, P.R.China.

\section{References}

1. King, A.M.Q., E.J. Lefkowitz, A.R. Mushegian, M.J. Adams, B.E. Dutilh, A.E. Gorbalenya, et al. Changes to taxonomy and the International Code of Virus Classification and Nomenclature ratified by the International Committee on Taxonomy of Viruses (2018). Arch Virol. 2018; 163: 2601-2631.

2. Bande, F., S.S. Arshad, A.R. Omar. Isolation and Metagenomic Identification of Avian Leukosis Virus Associated with Mortality in Broiler Chicken. Adv Virol. 2016; 2016: 9058403.

3. Su, Q., Y. Li, W. Li, S. Cui, S. Tian, Z. Cui, et al. Molecular characteristics of avian leukosis viruses isolated from indigenous chicken breeds in China. Poult Sci. 2018; 97: 2917-2925.

4. Bova, C.A., J.C. Olsen, R. Swanstrom. The avian retrovirus env gene family: molecular analysis of host range and antigenic variants. J Virol. 1988; 62: 75-83.

5. Smith, E.J., L.B. Crittenden, A.K. Whitson. Radioimmunoassay for the envelope glycoprotein of subgroup E avian leukosis-sarcoma viruses. Virology. 1978; 84: 331-40.

6. Salter, D.W., L.B. Crittenden. Artificial insertion of a dominant gene for resistance to avian leukosis virus into the germ line of the chicken. Theor Appl Genet. 1989; 77: 457-61.

7. Wu, Z.C., M.Z. Zhu, X.M. Bian, C.T. Ma, P. Zhao, Z.Z. Cui. [Comparison of whole genome sequences and replication ability in cell cultures between two avian leukosis viruses of subgroup B]. Bing Du 
Xue Bao. 2011; 27: 447-55.

8. Young, J.A., P. Bates, H.E. Varmus. Isolation of a chicken gene that confers susceptibility to infection by subgroup A avian leukosis and sarcoma viruses. J Virol. 1993; 67: 1811-6.

9. Stepanets, V., Z. Vernerova, M. Vilhelmova, J. Geryk, J. Plachy, J. Hejnar, et al. Intraembryonic avian leukosis virus subgroup $\mathrm{C}(\mathrm{ALV}-\mathrm{C})$ inoculation producing wasting disease in ducks soon after hatching. Folia Biol (Praha). 2003; 49: 100-9.

10. Fadly, A.M., W. Okazaki, L.B. Crittenden. Avian leukosis virus infection and congenital transmission in lines of chickens resisting selection for reduced shedding. Avian Dis. 1983; 27: 584-93.

11. Payne, L.N., S.R. Brown, N. Bumstead, K. Howes, J.A. Frazier, M.E. Thouless. A novel subgroup of exogenous avian leukosis virus in chickens. J Gen Virol. 1991; 72 ( Pt 4): 801-7.

12. Cui, Z., Y. Du, Z. Zhang, R.F. Silva. Comparison of Chinese field strains of avian leukosis subgroup J viruses with prototype strain HPRS-103 and United States strains. Avian Dis. 2003; 47: 1321-30.

13. Furukawa, S., K. Tsukamoto, M. Maeda. Multicentric histiocytosis related to avian leukosis virus subgroup J (ALV-J)-infection in meat-type local chickens. J Vet Med Sci. 2014; 76: 89-92.

14. Li, N., B. Xu, W. Dong, S. Qiao, L.F. Lee, H.M. Zhang, et al. Detection and localization of naturally transmitted avian leukosis subgroup $\mathrm{J}$ virus in egg-type chickens by in situ PCR hybridization. J Vet Med A Physiol Pathol Clin Med. 2007; 54: 553-8.

15. Spencer, J.L., M. Chan, S. Nadin-Davis. Relationship between egg size and subgroup J avian leukosis virus in eggs from broiler breeders. Avian Pathol. 2000; 29: 617-22.

16. Li, D., L. Qin, H. Gao, B. Yang, W. Liu, X. Qi, et al. Avian leukosis virus subgroup A and B infection in wild birds of Northeast China. Vet Microbiol. 2013; 163: 257-63.

17. Zhou, D., J. Xue, Y. Zhang, G. Wang, Y. Feng, L. Hu, et al. Outbreak of myelocytomatosis caused by mutational avian leukosis virus subgroup $\mathrm{J}$ in China, 2018. Transbound Emerg Dis. 2019; 66: 622626.

18. Li, Y., X. Liu, H. Liu, C. Xu, Y. Liao, X. Wu, et al. Isolation, identification, and phylogenetic analysis of two avian leukosis virus subgroup $\mathrm{J}$ strains associated with hemangioma and myeloid leukosis. Vet Microbiol. 2013; 166: 356-64.

19. Sun, S., Z. Cui. Epidemiological and pathological studies of subgroup J avian leukosis virus infections in Chinese local "yellow" chickens. Avian Pathol. 2007; 36: 221-6.

20. Yun, B., D. Li, H. Zhu, W. Liu, L. Qin, Z. Liu, et al. Development of an antigen-capture ELISA for the detection of avian leukosis virus p27 antigen. J Virol Methods. 2013; 187: 278-83.

21. Smith, L.M., S.R. Brown, K. Howes, S. McLeod, S.S. Arshad, G.S. Barron, et al. Development and application of polymerase chain reaction (PCR) tests for the detection of subgroup $\mathrm{J}$ avian leukosis virus. Virus Res. 1998; 54: 87-98.

22. Zhang, X., M. Liao, P. Jiao, K. Luo, H. Zhang, T. Ren, et al. Development of a loop-mediated isothermal amplification assay for rapid detection of subgroup J avian leukosis virus. J Clin Microbiol. 2010; 48: 2116-21. 
23. Yu, B., Y. An, G. Xu, H. Shan. Detection of Chlamydia trachomatis and Neisseria gonorrhoeae based on cross-priming amplification. Lett Appl Microbiol. 2016; 62: 399-403.

24. Wang, Y.X., A.Y. Zhang, Y.Q. Yang, C.W. Lei, G.Y. Cheng, W.C. Zou, et al. Sensitive and rapid detection of Salmonella enterica serovar Indiana by cross-priming amplification. J Microbiol Methods. 2018; 153: $24-30$.

25. Wang, Y., L. Sun, J.Q. Li, Z.M. Wang, W.W. Jiao, J. Xiao, et al. Detection of Nucleic Acids and Prevention of Carryover Contamination Using Cross-Priming Amplification Combined with Nanoparticles-Based Biosensor and Antarctic Thermal Sensitive Uracil-DNA-Glycosylase. J Biomed Nanotechnol. 2019; 15: 878-892.

26. Xu, G., L. Hu, H. Zhong, H. Wang, S. Yusa, T.C. Weiss, et al. Cross priming amplification: mechanism and optimization for isothermal DNA amplification. Sci Rep. 2012; 2: 246.

27. Liu, W., Y. Zhou, Y. Fan, N. Jiang, K. Cain, L. Zeng. Development of cross-priming amplification coupled with vertical flow visualization for rapid detection of infectious spleen and kidney necrosis virus (ISKNV) in mandarin fish, Siniperca chuatsi. J Virol Methods. 2018; 253: 38-42.

28. Gou, H., J. Li, R. Cai, S. Song, M. Li, D. Yang, et al. Rapid detection of Haemophilus parasuis using cross-priming amplification and vertical flow visualization. J Microbiol Methods. 2018; 144: 67-72.

29. Parida, M., J. Shukla, S. Sharma, S. Ranghia Santhosh, V. Ravi, R. Mani, et al. Development and evaluation of reverse transcription loop-mediated isothermal amplification assay for rapid and realtime detection of the swine-origin influenza A H1N1 virus. J Mol Diagn. 2011; 13: 100-7.

30. Feng, T., S. Li, S. Wang, J. Pan. Cross priming amplification with nucleic acid test strip analysis of mutton in meat mixtures. Food Chem. 2018; 245: 641-645.

31. Dai, M., M. Feng, D. Liu, W. Cao, M. Liao. Development and application of SYBR Green I real-time PCR assay for the separate detection of subgroup $\mathrm{J}$ Avian leukosis virus and multiplex detection of avian leukosis virus subgroups A and B. Virol J. 2015; 12: 52.

32. Chesters, P.M., L.P. Smith, V. Nair. E (XSR) element contributes to the oncogenicity of Avian leukosis virus (subgroup J). J Gen Virol. 2006; 87: 2685-92.

33. Kuta, A., G. Wozniakowski, M.P. Polak. Cross-priming amplification for detection of bovine viral diarrhoea virus species 1 and 2. J Appl Microbiol. 2015; 119: 632-9.

34. Yang, H.L., J. Huang, B. Yang, F. Liu, Q.L. Zhang. The establishment and application of isothermal cross-priming amplification techniques in detecting penaeid shrimp white spot syndrome virus. Lett Appl Microbiol. 2014; 59: 200-6.

\section{Tables}

Table 1. Primer and probe sequences 


\begin{tabular}{cc}
\hline Primer & Sequence $55^{\prime}-3^{\prime} \square$ \\
\hline F3 & AGGATGAGGTGATAAGAAA \\
B3 & ACCGAACCAAAGGTAACACACG \\
B2 & CAAGCAGGTGCGGAATGG \\
F2 & Biotin-GGAAAGGTGAGCAAGAAGG \\
F1 & FAM-CGCCAGCAACAAGCAAGAAA \\
CPR & GGAAAGGGAGCAAGAAGGCAAGCAGGTGCGGAATGG \\
\hline
\end{tabular}

Table 2. Different primer concentration combinations

\begin{tabular}{cccccc}
\hline Primer groups & \multicolumn{5}{c}{ Working concentration $\left(\mu \mathrm{mol} \cdot \mathrm{L}^{-1}\right)$} \\
\cline { 2 - 6 } & F3 & B3 & F2 & F1 & CPR \\
\hline 1 & 0.4 & 0.4 & 0.6 & 0.6 & 0.8 \\
2 & 0.4 & 0.4 & 0.8 & 0.8 & 1.0 \\
3 & 0.4 & 0.4 & 0.6 & 0.6 & 1.0 \\
4 & 0.4 & 0.4 & 0.6 & 0.6 & 1.2 \\
5 & 0.2 & 0.2 & 0.8 & 0.8 & 1.2 \\
6 & 0.2 & 0.2 & 0.4 & 0.4 & 0.6 \\
7 & 0.2 & 0.2 & 0.8 & 0.8 & 1.0 \\
8 & 0.2 & 0.2 & 0.6 & 0.6 & 1.0 \\
9 & 0.6 & 0.6 & 0.8 & 0.8 & 1.0 \\
10 & 0.6 & 0.6 & 1.0 & 1.0 & 1.2 \\
11 & 0.6 & 0.6 & 0.8 & 0.8 & 1.2 \\
\hline
\end{tabular}

Table 3. Optimal ALV-J CPA reaction system and conditions 


\begin{tabular}{|c|c|c|}
\hline Component & Volume $(\mu \mathrm{L})$ & $\begin{array}{l}\text { Working } \\
\text { concentration }\end{array}$ \\
\hline 10× ThermoPol Buffer & 2.5 & $1 \times$ \\
\hline $5 \mathrm{~mol} \mathrm{~L}^{-1}$ Betaine & 1.0 & $0.2 \mathrm{~mol} \mathrm{~L}^{-1}$ \\
\hline $10 \mathrm{mmol} \mathrm{L}^{-1} \mathrm{dNTPs}$ & 1.5 & $0.6 \mathrm{mmol} \mathrm{L}^{-1}$ \\
\hline $100 \mathrm{mmol} \mathrm{L}^{-1} \mathrm{Mg}^{2+}$ & 1.0 & $4.0 \mathrm{mmol} \mathrm{L}^{-1}$ \\
\hline $8 \mathrm{U} \mu \mathrm{L}^{-1}$ Bst DNA polymerase & 1.0 & 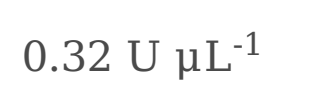 \\
\hline $10 \mu \mathrm{mol} \mathrm{L}{ }^{-1} \mathrm{CPR}$ & 2.5 & $1.0 \mu \mathrm{mol} \mathrm{L}-1$ \\
\hline $10 \mu \mathrm{mol} \mathrm{L}{ }^{-1} \mathrm{~F} 1$ & 2.0 & $0.8 \mu \mathrm{mol} \mathrm{L}-1$ \\
\hline $10 \mu \mathrm{mol} \mathrm{L}{ }^{-1} \mathrm{~F} 2$ & 2.0 & $0.8 \mu \mathrm{mol} \mathrm{L}-1$ \\
\hline $10 \mu \mathrm{mol} \mathrm{L}-1$ B3 & 0.5 & $0.2 \mu \mathrm{mol} \mathrm{L}-1$ \\
\hline $10 \mu \mathrm{mol} \mathrm{L}-1 \mathrm{~F} 3$ & 0.5 & $0.2 \mu \mathrm{mol} \mathrm{L}-1$ \\
\hline DNA template & 1.0 & I \\
\hline $\mathrm{ddH}_{2} \mathrm{O}$ & Add to $25 \mu \mathrm{L}$ & l \\
\hline Amplification for $60 \mathrm{~min}$ at $60^{\circ}$ & & \\
\hline
\end{tabular}

Table 4. Detection results for plasma samples with $\mathrm{S} / \mathrm{P}>0.2$

\begin{tabular}{|c|c|c|c|c|c|c|}
\hline \multirow{2}{*}{\multicolumn{2}{|c|}{$\begin{array}{c}\text { No. } \\
\text { Detected }\end{array}$}} & \multicolumn{2}{|c|}{ RT-PCR } & \multicolumn{2}{|c|}{ PCR } & \multirow[t]{2}{*}{ Total } \\
\hline & & Positive & Negative & Positive & Negative & \\
\hline \multirow[t]{2}{*}{ CPA } & Positive & 26 & 0 & 25 & 1 & 26 \\
\hline & Negative & 0 & 22 & 0 & 22 & 22 \\
\hline \multicolumn{2}{|c|}{ Total } & 26 & 22 & 25 & 23 & 48 \\
\hline
\end{tabular}

Table 5. Detection results for plasma samples with $0.1 \leq \mathrm{S} / \mathrm{P} \leq 0.2$ 


\begin{tabular}{|c|c|c|c|c|c|c|}
\hline \multirow{2}{*}{\multicolumn{2}{|c|}{$\begin{array}{c}\text { No. } \\
\text { Detected }\end{array}$}} & \multicolumn{2}{|c|}{ RT-PCR } & \multicolumn{2}{|c|}{ PCR } & \multirow[t]{2}{*}{ Total } \\
\hline & & Positive & Negative & Positive & Negative & \\
\hline \multirow[t]{2}{*}{ CPA } & Positive & 45 & 0 & 29 & 16 & 45 \\
\hline & Negative & 2 & 28 & 0 & 30 & 30 \\
\hline \multicolumn{2}{|c|}{ Total } & 47 & 28 & 29 & 46 & 75 \\
\hline
\end{tabular}

\section{Figures}

CCGGCATCACCCAAAAGGATGAGGTGACTAAGAAAGATGAGGCGAGCCCTCTCTTTGC F2

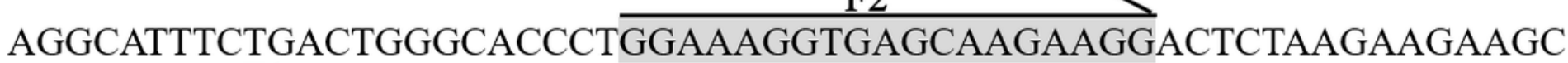
$\frac{\mathrm{F} 1}{\text { CGCCAGCAACAAGCAAGAAAGACCCGGAGAAGACACCCTTGCTGCCGTCGAGAGGTT }}$ ATTTCTTCTTTCAAATGATACTTGTGTGCGTGGTTATTATTTCTGTTGTCCCAGGGGTGAA GGGAGTTCATCTGTTGCAACAACCAGGAAACGTGTGGGTCACCTGGGCAAATAAGACG GGCCAAACAGATTTTTGCCTTAGTCTGCAGTCAGCGACCTCGCCATTCCGCACCTGCTTG ATAGGCATTCCACAGTATCCTCTGAGCACCTTTGAGGGATATGTCACTAATGTTACTGCCT GCCAAAACGACACCGATTTAGCCAGCCAAACAGCATGCTTGATACAGACTCTAAATACG $F$

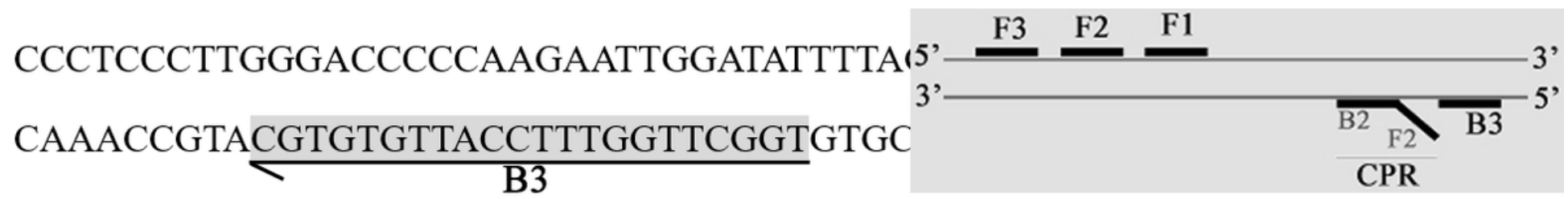
Figure 1

The specific positions and sequence of CPA primers and probes in the genome 

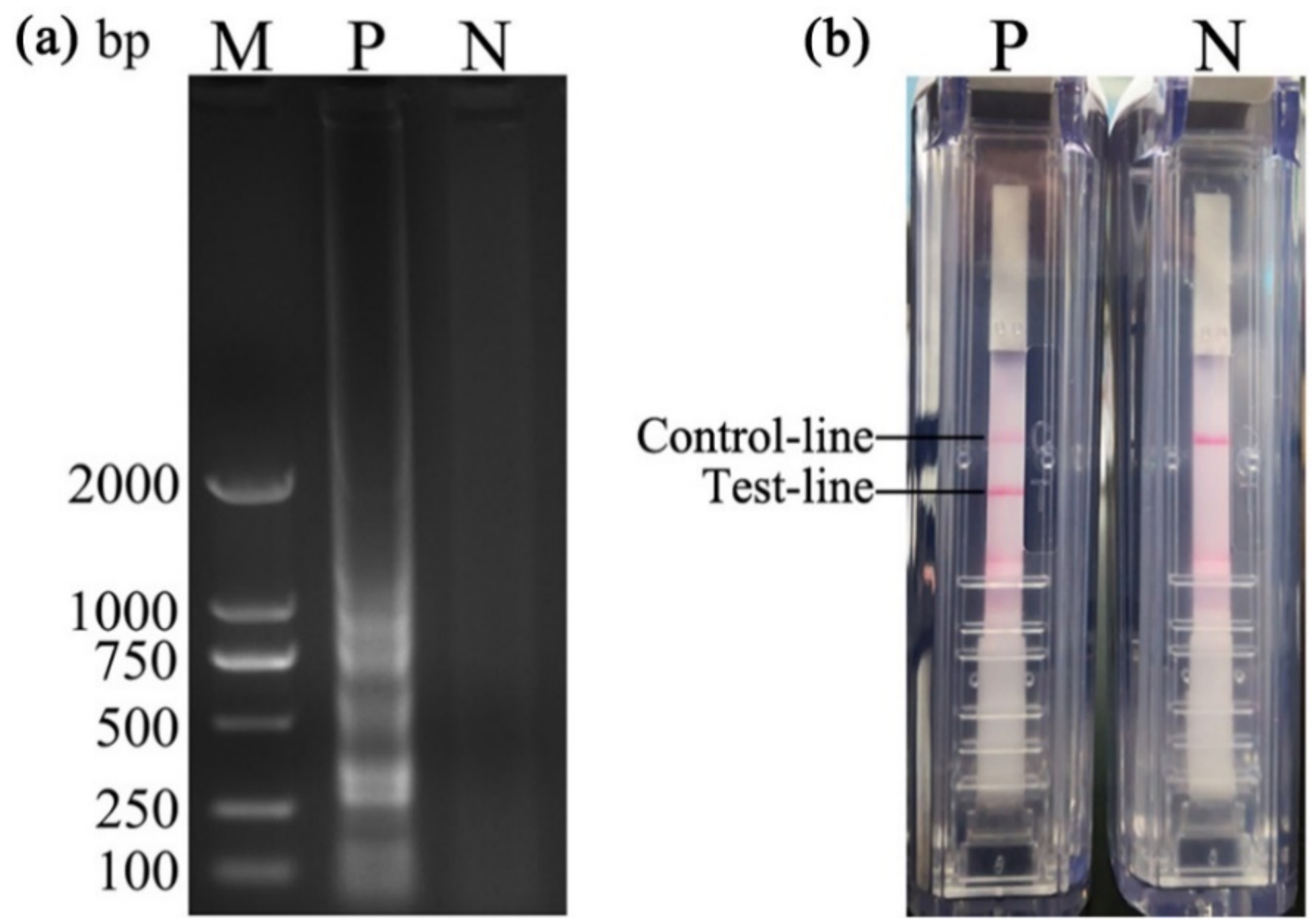

\section{Figure 2}

The basic reaction system of ALV-J CPA. (a) Analysis of the CPA method by agarose gel electrophoresis. Lane M, DS2000 DNA markers; P, recombinant plasmid standards; N, negative control. (b) Analysis by the CPA method with nucleic acid test strips. Lane P, recombinant plasmid standards; N, negative control.

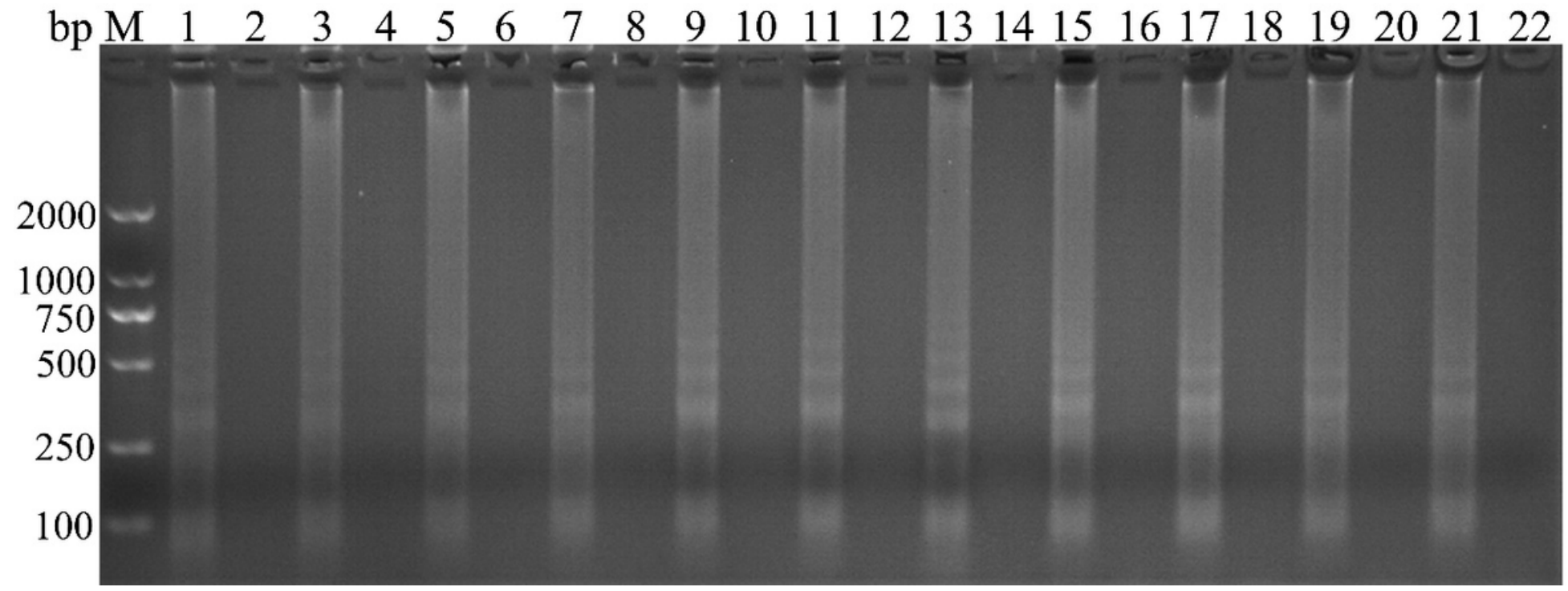




\section{Figure 3}

Analysis of ALV-J CPA at different concentration of primers (Table 2) by agarose gel electrophoresis. Lane M, DS2000 DNA markers; $1,3,5,7,9,11,13,15,17,19,21$, were primers groups 1-11 (Table 2) respectively; $2,4,6,8,10,12,14,16,18,20$ and 22 were negative controls for the corresponding primers groups.
$\mathrm{bp} \mathrm{M}$
2

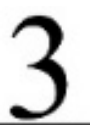
4

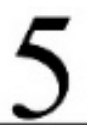
6
7

\section{0}

\section{0}

750

500

250

100

\section{Figure 4}

Analysis of ALV-J CPA at different concentration of Mg2+ by agarose gel electrophoresis. Lane M, DS2000 DNA markers; 1: 0 mmol L-1; 2: 1 mmol L-1; 3: 2 mmol L-1; 4: 3 mmol L-1; 5: 4 mmol L-1; 6: 5 mmol L-1. 


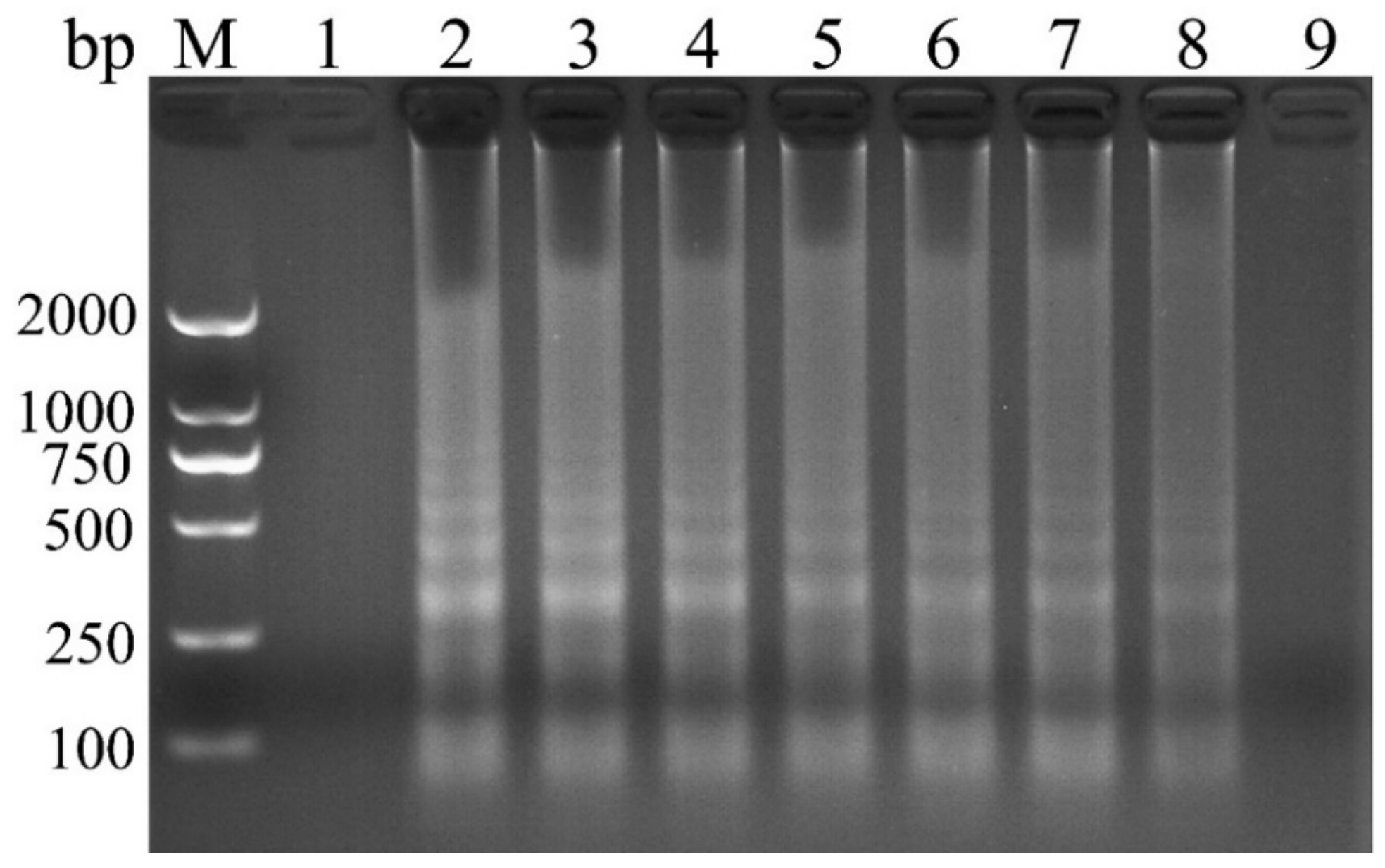

Figure 5

Analysis of ALV-J CPA at different concentration of Betaine by agarose gel electrophoresis. Lane $\mathrm{M}$, DS2000 DNA markers; 1: 0 mol L-1; 2: 0.2 mol L-1; 3: 0.4 mol L-1; 4: 0.6 mol L-1; 5: 0.8 mol L-1; 6: 1.0 mol L-1; 7: $1.2 \mathrm{~mol} \mathrm{L-1;} \mathrm{8:} 1.4 \mathrm{~mol} \mathrm{L-1.}$ 


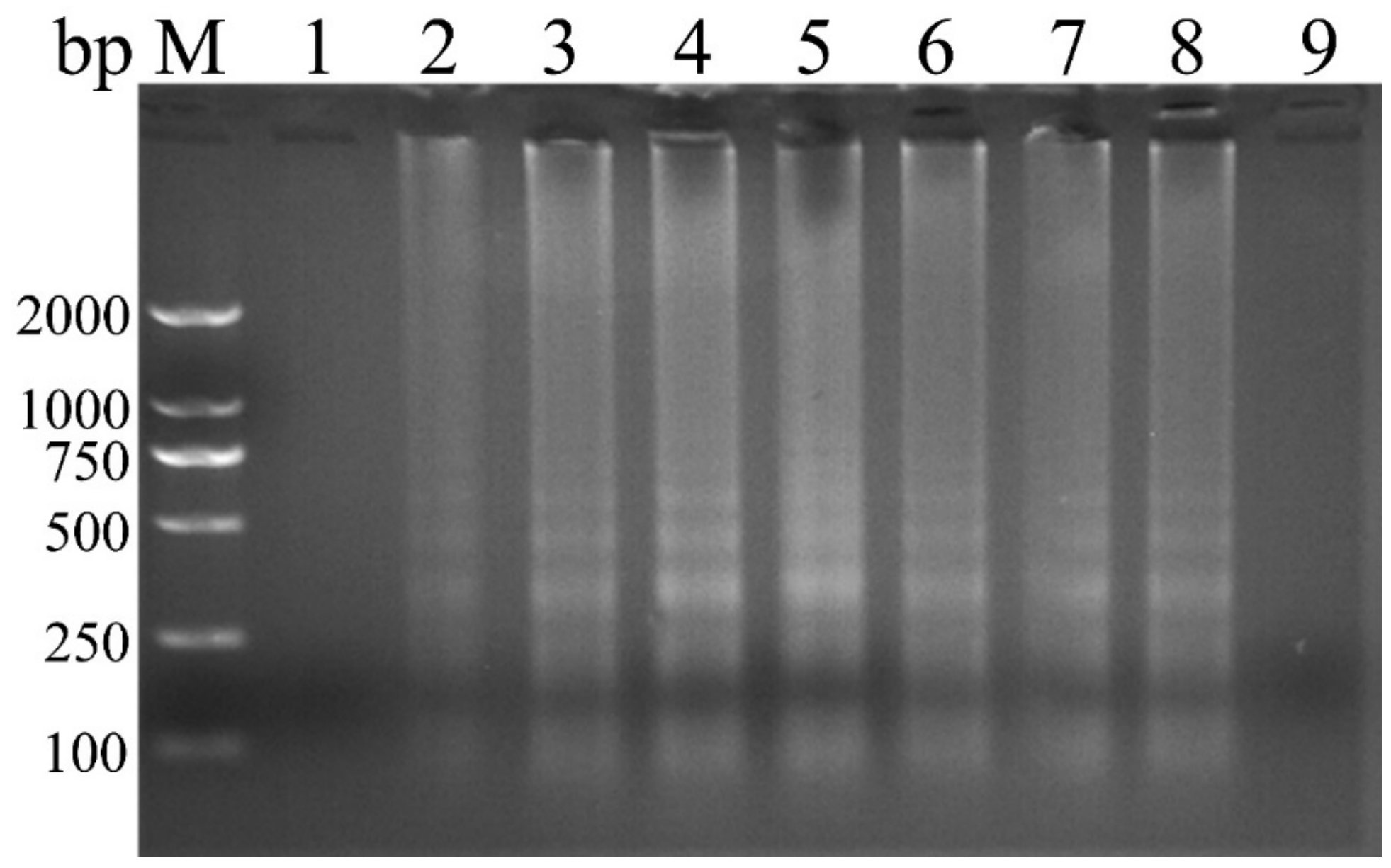

\section{Figure 6}

Analysis of ALV-J CPA at different concentration of dNTPs by agarose gel electrophoresis. Lane M, DS2000 DNA markers; 1: 0 mmol L-1; 2: 0.2 mmol L-1; 3: 0.4 mmol L-1; 4: 0.6 mmol L-1; 5: 0.8 mmol L-1; 6: $1.0 \mathrm{mmol} \mathrm{L-1;} \mathrm{7:} 1.2 \mathrm{mmol} \mathrm{L-1;} \mathrm{8:} 1.4 \mathrm{mmol} \mathrm{L-1.}$ 


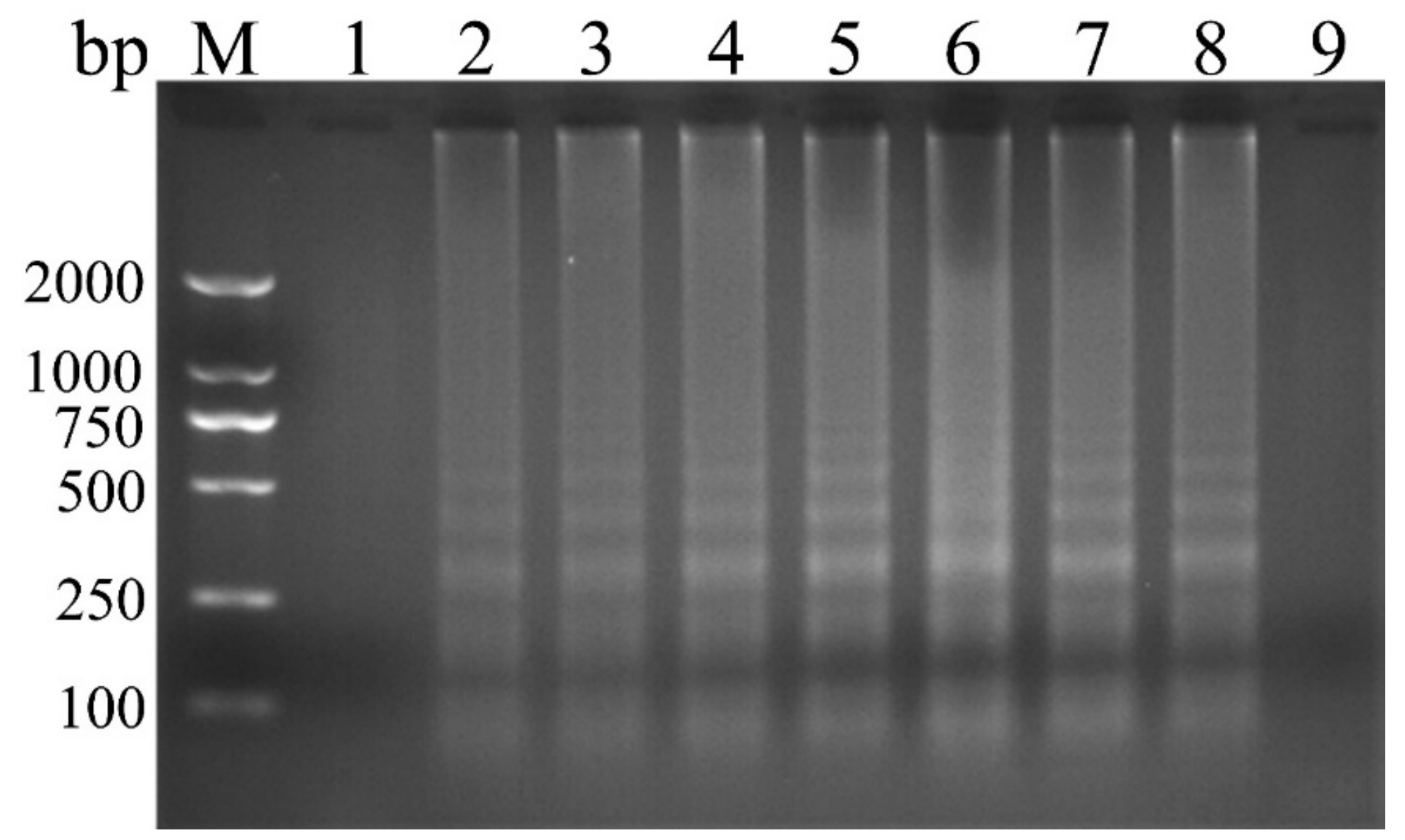

\section{Figure 7}

Analysis of ALV-J CPA at different units of Bst DNA polymerase ( 8 units $\mu \mathrm{L}-1$ ) by agarose gel electrophoresis. Lane M, DS2000 DNA markers; 1: $0 \mu \mathrm{L} ; 2: 0.2 \mu \mathrm{L} ; 3: 0.4 \mu \mathrm{L} ; 4: 0.6 \mu \mathrm{L} ; 5: 0.8 \mu \mathrm{L} ; 6: 1.0 \mu \mathrm{L}$; 7: $1.5 \mu \mathrm{L} ; 8: 2.0 \mu \mathrm{L}$.

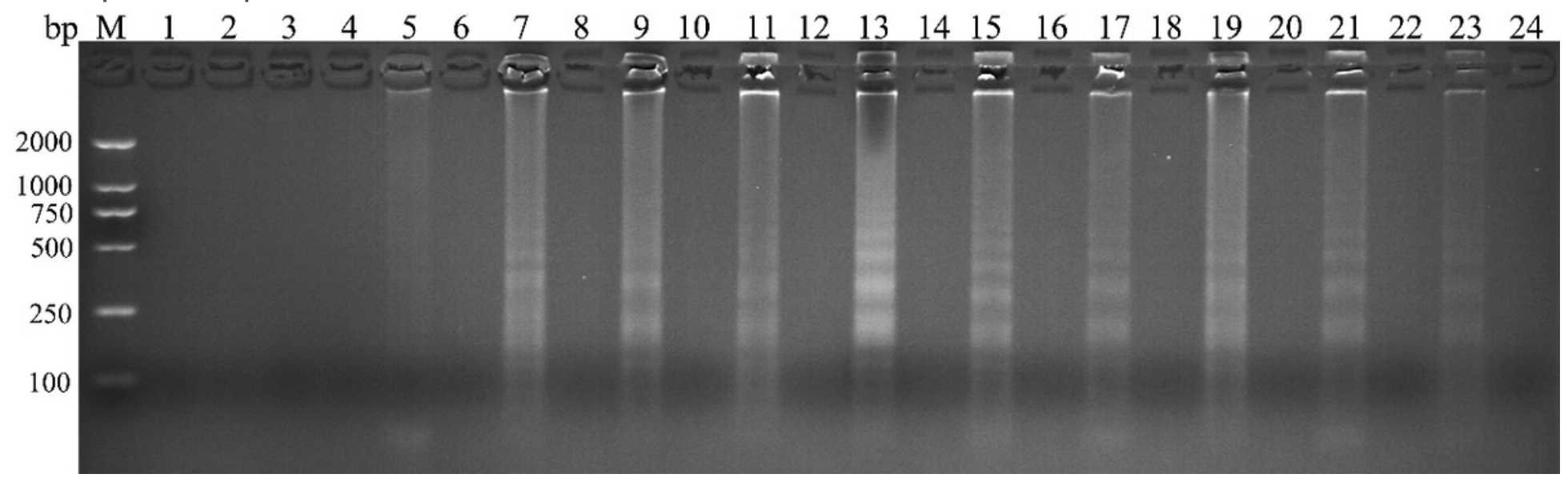

\section{Figure 8}

Analysis of ALV-J CPA at different temperatures by agarose gel electrophoresis. Lane M, DS2000 DNA markers; $1,54^{\circ} \mathrm{C} ; 3,55^{\circ} \mathrm{C} ; 5,56^{\circ} \mathrm{C} ; 7,57^{\circ} \mathrm{C} ; 9,58^{\circ} \mathrm{C} ; 11,59^{\circ} \mathrm{C} ; 13,60^{\circ} \mathrm{C} ; 15,61^{\circ} \mathrm{C} ; 17,62^{\circ} \mathrm{C} ; 19,63^{\circ} \mathrm{C} ; 21,64^{\circ} \mathrm{C}$; 
$23,65^{\circ} \mathrm{C} ; 2,4,6,8,10,12,14,16,18,20,22$ and 24 were negative controls for the corresponding temperatures.
bp M
1
23
45
6
7
8
9

2000

1000

750

500

250

100

\section{Figure 9}

Analysis of ALV-J CPA with different reaction times by agarose gel electrophoresis. Lane M, DS2000 DNA markers; 1, 15 min; 2, 30 min; 3, 45 min; 4, 60 min; 5, 75 min; 6, 90 min; 7, 105 min; 8, 120 min; 1, Negative control amplification for $120 \mathrm{~min}$.

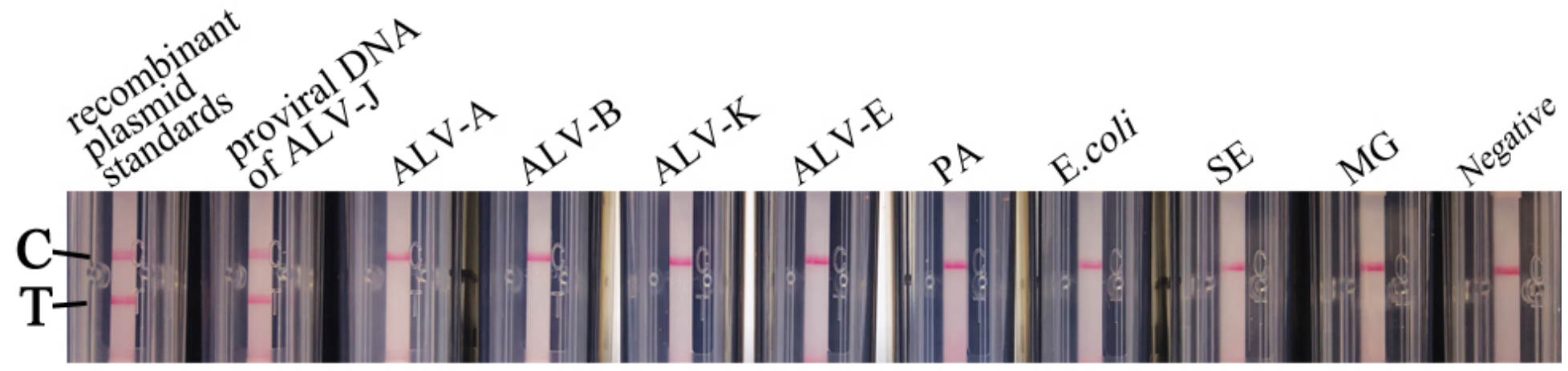

Figure 10

Analysis of the specificity of the ALV-J CPA method. 
(a)

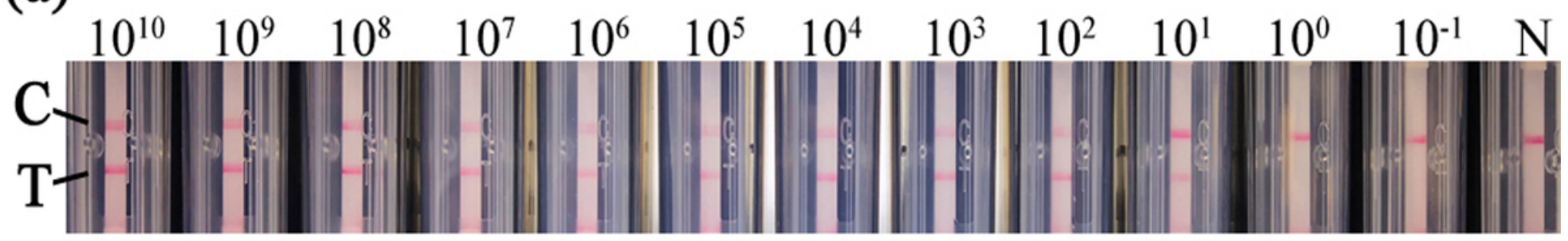

(b)
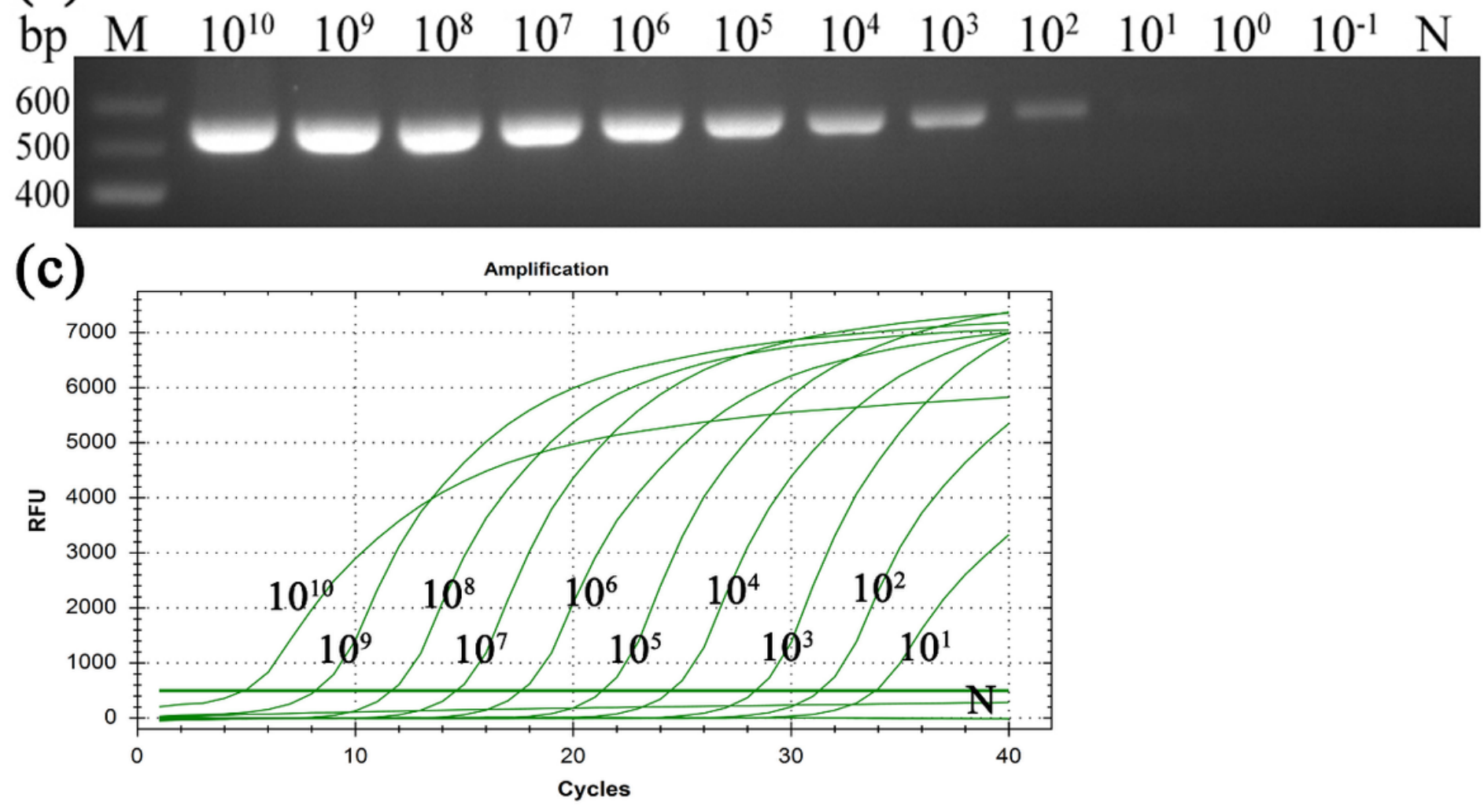

Figure 11

Comparison of sensitivity between the CPA, PCR and RT-PCR of ALV-J detect methods based on recombinant plasmid standards at different copy numbers. (a) Sensitivity of CPA based on a nucleic acid detection device. N, negative control. (b) Sensitivity of conventional PCR. N, negative control. (c) Sensitivity of RT-PCR for ALV-J. N, negative control. 